\title{
A PRELIMINARY SURVEY OF POTENTIAL FAST REACTOR CONTROL MATERIALS
}

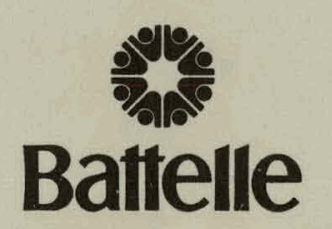

Pacific Northwest Laboratories Richland, Washington 99352

\section{AUGUST 1973}




\section{DISCLAIMER}

This report was prepared as an account of work sponsored by an agency of the United States Government. Neither the United States Government nor any agency Thereof, nor any of their employees, makes any warranty, express or implied, or assumes any legal liability or responsibility for the accuracy, completeness, or usefulness of any information, apparatus, product, or process disclosed, or represents that its use would not infringe privately owned rights. Reference herein to any specific commercial product, process, or service by trade name, trademark, manufacturer, or otherwise does not necessarily constitute or imply its endorsement, recommendation, or favoring by the United States Government or any agency thereof. The views and opinions of authors expressed herein do not necessarily state or reflect those of the United States Government or any agency thereof. 


\section{DISCLAIMER}

Portions of this document may be illegible in electronic image products. Images are produced from the best available original document. 


\title{
NOTICE
}

The report was prepared as an account of work sponsored by the United States Covernment. Neither the United States nor the United States Atomic Energy Commission, nor any of their employees, nor any of their contractors, subcontractors, or their employees, makes any warranty, express or implied. or assumes any legal liability or responsibility for the accuracy, completeness or usefulness of any information, apparatus, product or process disclosed, or represents that its use would not infringe privately owned rights.

\author{
PACIFIC NORTHWEST LABORATORY \\ operated by \\ BATTELLE \\ for the \\ U.S. ATOMIC ENERGY COMMISSION \\ Under Contract AT(45-1)-1830
}

\footnotetext{
Printed in the United States of America

- Available from

National Technical Information Service

U.S. Department of Commerce

5285 Port Royal Road

Springfield, Virginia 22151

Price: Printed Copy 4.00; Microfiche \$0.95
} 


\title{
A PRELIMINARY SURVEY OF
}

POTENTIAL FAST REACTOR CONTROL MATERIALS

by

\author{
W. J. Gray
}

Ceramics and Graphite Section

Fuels and Materials Department

\section{Augus.t 1973}

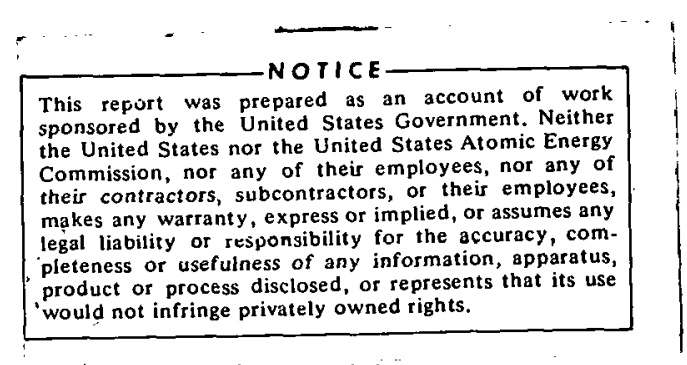

BATTELLE

PACIFIC NORTHWEST LABORATORIES

RICHLAND, WASHINGTON 99352 


\section{TABLE OF CONTENTS}

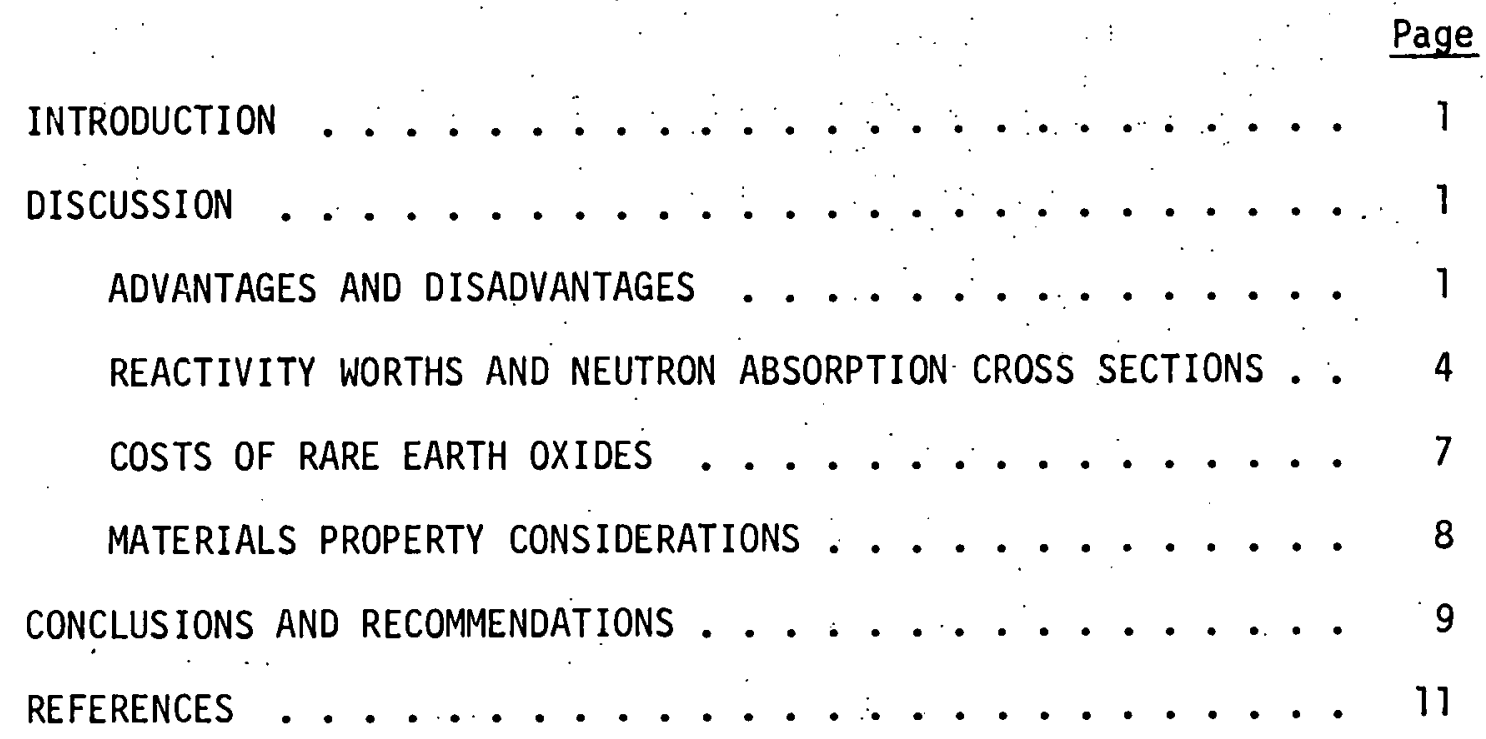




\section{INTRODUCTION}

Potential control materials for fast reactors, both Liquid Metal Fast Breeder Reactors (LMFBR) and Gas-Cooled Fast Breeder Reactors (GCFBR), are limited because of the requirement for high neutron absorption cross sections at high neutron energies. Possibilities include $\mathrm{B}^{10}, \mathrm{Ta}$, and several of the rare earths (RE), particularly europium. Boron is usually considered for use as $B_{4} C$, either natural or enriched in $B^{10}$, while the RE would normally be employed as oxides. Natural $B_{4} C$ and Ta are relatively inexpensive (roughly $\$ 20$ per pound and $\$ 28$ per pound, respectively) but $\mathrm{B}^{10}$. enrichment costs are quite high $\left(\mathrm{B}_{4} \mathrm{C}\right.$ enriched to $92 \% \mathrm{~B}^{10}$, for example, costs approximately $\$ 3,600$ per pound). The cost of pure RE oxides of potential interest varies from about $\$ 30$ per pound for $\mathrm{Sm}_{2} \mathrm{O}_{3}$ to about $\$ 365$ per pound for $\mathrm{Eu}_{2} \mathrm{O}_{3}$.

This report briefly discusses the advantages and disadvantages of $\mathrm{B}_{4} \mathrm{C}, \mathrm{Ta}$, and the RE oxides and, in particular, examines the possible cost savings that may be realized by using some RE oxide (or mixtures thereof) rather than pure $\mathrm{Eu}_{2} \mathrm{O}_{3}$ as a control material.

\section{DISCUSSION}

\section{A. ADVANTAGES AND DISADVANTAGES}

Before discussing other advantages and disadvantages, it is interesting to compare raw material costs for a large reactor assuming natural $\mathrm{B}_{4} \mathrm{C}, \mathrm{Ta}$, and $\mathrm{Eu}_{2} \mathrm{O}_{3}$ cost $\$ 20, \$ 28$, and $\$ 365$ per pound, respectively. The $1000 \mathrm{MW}(\mathrm{e})$ LMFBR conceptual design proposed by Westinghouse ${ }^{(1)}$ uses 60 Ta control rods with a total Ta volume of $0.22 \mathrm{~cm}^{3}$ or 8,000 pounds costing $\$ 225,000$. Based on data presented in Section $B$, this is equivalent to 2,600 pounds of $\mathrm{Eu}_{2} \mathrm{O}_{3}$ costing $\$ 950,000$ and to 1,070 pounds of natural $\mathrm{B}_{4} \mathrm{C}$ costing $\$ 21,400$. If enriched rather than natural $\mathrm{B}_{4} \mathrm{C}$ were used, its cost could go even higher than that for $\mathrm{Eu}_{2} \mathrm{O}_{3}$. 
Costs and neutron absorption cross sections of other RE oxides are discussed later, but just a glance at Table I suggests the possibility that substantial cost savings could result from the use of RE oxides other than $\mathrm{Eu}_{2} \mathrm{O}_{3}$.

Raw materials costs, of course, represent only a fraction of the total cost of the control elements for a reactor. Other costs include those of fabricating pellets or other useable forms and incorporating these into the control rod assemblies. If a material with lower worth per unit volume requires additional control rod assemblies, these costs could offset the reduced cost of the raw material. A detailed economic analysis tied very closely to the physics considerations would be required to determine whether the cheapest material is, in fact, the best way to go. It will become obvious later that such an analysis which includes RE oxides other than $\mathrm{Eu}_{2} \mathrm{O}_{3}$ is not possible at the present time because of the lack of physics data.

$\mathrm{B}_{4} \mathrm{C}$ enriched in $\mathrm{B}^{10}$ has the highest macroscopic absorption cross section of any of the potential control materials for the neutron energies of interest. The choice of using either natural $\mathrm{B}_{4} \mathrm{C}$ or varying degrees of enrichment in $B^{10}$ offers a wide range of reactivity worth. One must keep in mind, however, that enrichment costs are very high. Disadvantages of ${ }_{B}{ }_{4}$ are the helium production via the $B^{10}(n, \alpha) L^{7}$ reaction, the high cost of hot-pressing the $\mathrm{B}_{4} \mathrm{C}$ powder into pellets, and possibly burn-out of the $B^{10}$ thereby limiting the useful lifetime of the control element.

Helium produced in the $\mathrm{B}_{4} \mathrm{C}$ must either be contained in the control pin or vented to the reactor. Presumably venting would be relatively easy in GCFBR's but one must consider the possibility of moisture, which may get into the helium coolant via heat exchanger leaks, entering the control pins. The Hanford Engineering Development Laboratory (HEDL) operated by Westinghouse Hanford Company is currently trying to develop vents for LMFBR's which will release helium to the reactor sodium, and thus the reactor cover-gas, but prevent sodium ingress to the $\mathrm{B}_{4} \mathrm{C}$ in the control pin. 


\section{TABLE I}

RELATIVE ABUNDANCE* OF RARE EARTH ELEMENTS IN BASTNASITE AND PRICES OF THE 99.9\% PURE OXIDES

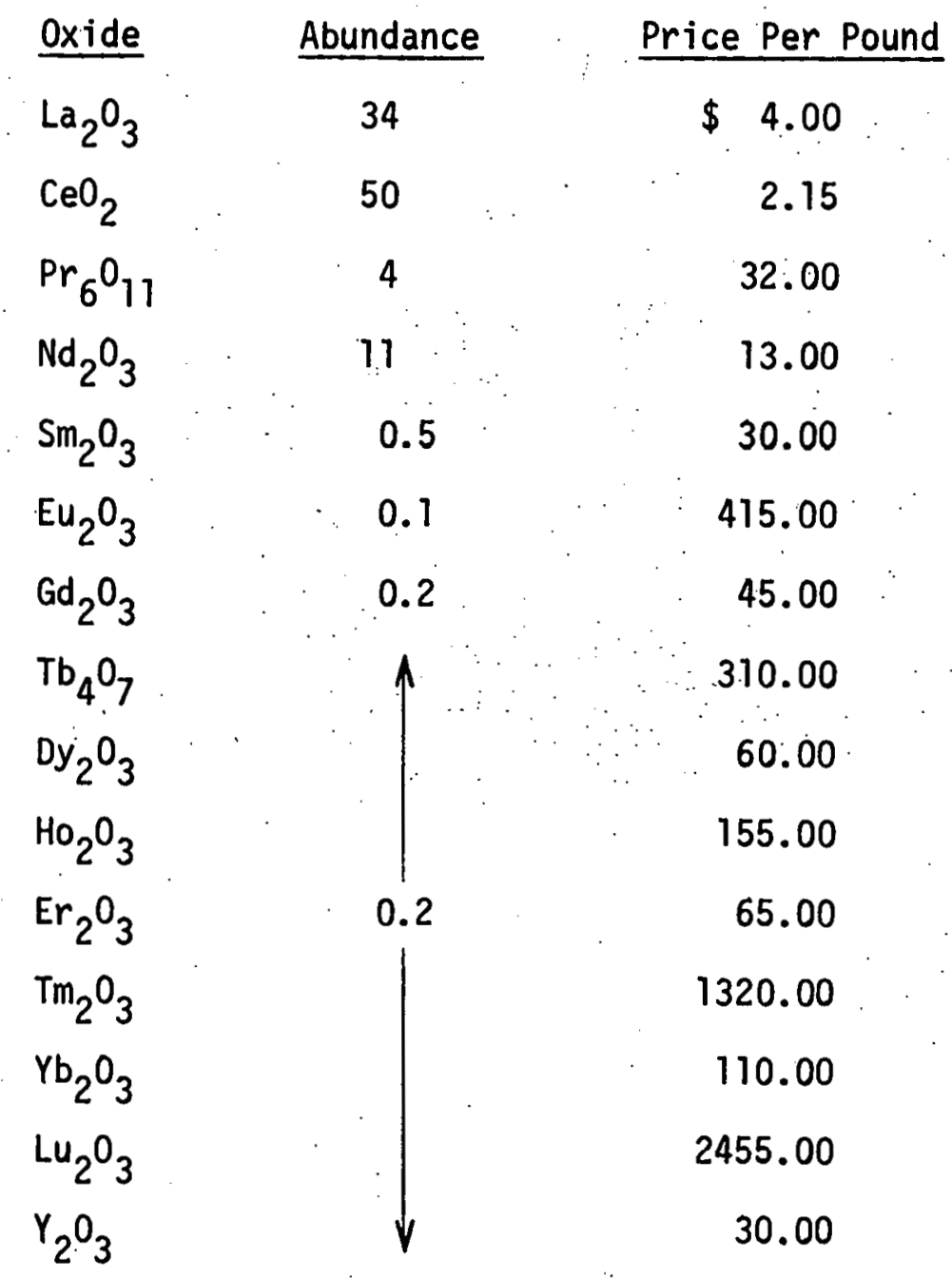

\footnotetext{
* $Y$ and the heavy rare earths, those with atomic numbers of 64 and greater, are often obtained from minerals which are richer in these materials than is bastnasite.
} 
If successful, this would allow fewer but larger-diameter and thinner-walled pins to be used. Vented pins together with the requirement for fewer largerdiameter pellets would result in a substantial cost reduction.

It is frequently stated that burn-out of the $B^{10}$ would limit the lifetime of $\mathrm{B}_{4} \mathrm{C}$ as a control material. Bowing of the control pins due to radiation-induced swelling of the stainless steel cladding, however, may prove just as restrictive.

Ta is easily fabricated and is compatible with sodium. Its high density, however, results in heavy control rods which require robust driving mechanisms. Furthermore, its high radioactive decay heat requires cooling. long after reactor shutdown.

Advantages of the RE oxides are as follows. No helium is produced thereby eliminating the venting problem. Pellet size would be limited primarily by thermal conductivity considerations. Pellets could be prepared by sintering at a fraction of the hot-pressing costs required for $B_{4} C$. Final grinding costs for RE oxides would be less than for $B_{4} C$ because $\mathrm{B}_{4} \mathrm{C}$ is much harder. Because of the large cross sections of the nuclides produced in $\mathrm{Eu}_{2} \mathrm{O}_{3}$, and perhaps other RE oxides as well, their worths would be nearly constant with time. Radioactive decay heat is much less than that in Ta but more than in $\mathrm{B}_{4} \mathrm{C}$. Finally, the lower density of RE oxides relative to $\mathrm{Ta}$ reduces control-rod drive requirements.

\section{B. REACTIVITY WORTHS AND NEUTRON ABSORPTION CROSS SECTIONS}

Tuttle and Springer ${ }^{(2)}$ have determined the specific reactivity of boron, $B^{10}$, Eu and Ta at infinite dilution in a typical LMFBR spectrum. Information presented in Table II was recalculated from their data on a volume basis. $\mathrm{Eu}_{2} \mathrm{O}_{3}$ has a higher worth per unit volume than either natural $B_{4} C$ or $T a$. The $B_{4} C$, of course, could be enriched in $B^{10}$ to yield worths higher than $\mathrm{Eu}_{2} \mathrm{O}_{3}$ but only at a substantial cost penalty. The spectrum in a GCFBR is harder than that in a LMFBR and a comparison of the relative reactivity worths of these three materials in a GCFBR spectrum is not available. 


\title{
TABLE II
}

\begin{abstract}
RELATIVE REACTIVITY WORTHS PER UNIT VOLUME*
IN A TYPICAL LMFBR SPECTRUM
\end{abstract}

$\begin{array}{lc}\text { Material } & \text { Relative Worth } \\ \mathrm{B}_{4} \mathrm{C} & 1.00 \\ \mathrm{Ta} & 0.87 \\ \mathrm{Eu}_{2} \mathrm{O}_{3} & 1.19\end{array}$

* Reactivity worths were calculated on the basis of infinite dilution
and $100 \%$ theoretical density for all materials. The cubic crystalline
form of Eu $\mathrm{O}_{3}$ was assumed.

Self-absorption is greater in Ta than in either $\mathrm{B}_{4} \mathrm{C}$ or $\mathrm{Eu}_{2} \mathrm{O}_{3},(2)$ so Ta would have an even less favorable relative worth than shown in Table II in a real control element. On the other hand, densities of $\mathrm{B}_{4} \mathrm{C}$ and $\mathrm{Eu}_{2} \mathrm{O}_{3}$ would probably be $290 \%$ theoretical density which would tend to compensate for the higher self-absorption of Ta.

The high cost of $\mathrm{Eu}_{2} \mathrm{O}_{3}$ provides incentive to look at other rare earths for potential control materials. Figure 1 shows $n, \alpha$ cross sections for $B^{10}$ and $n, y$ cross sections $(3)$ for the natural isotopic abundance of those RE with the highest cross sections and also for Ta. Unfortunately, this information provides only a very crude estimate of the relative worths of these elements. Such an estimate is, in fact, virtually impossible in the present case because of the complexity of the reactivity worth parameter together with the fact that the data for most of the elements exists only for the natural isotopic abundance and even then extend only up to $2200 \mathrm{keV}$ The situation with regard to GCFBR's is even worse because of their harder spectrum. It has been estimated, (4) however, that the cross sections and reactivity worths of the RE elements could be calculated for $\sim \$ 10,000$ each.

All that can be said at this point, therefore, is that one would guess that $\mathrm{Eu}$ has the highest worth. Tb and Ho also appear attractive but they too are rather expensive. Tm seems out of the question because of its high cost but $\mathrm{Sm}$ and Gd are nearly a factor of 10 less expensive than Eu. 


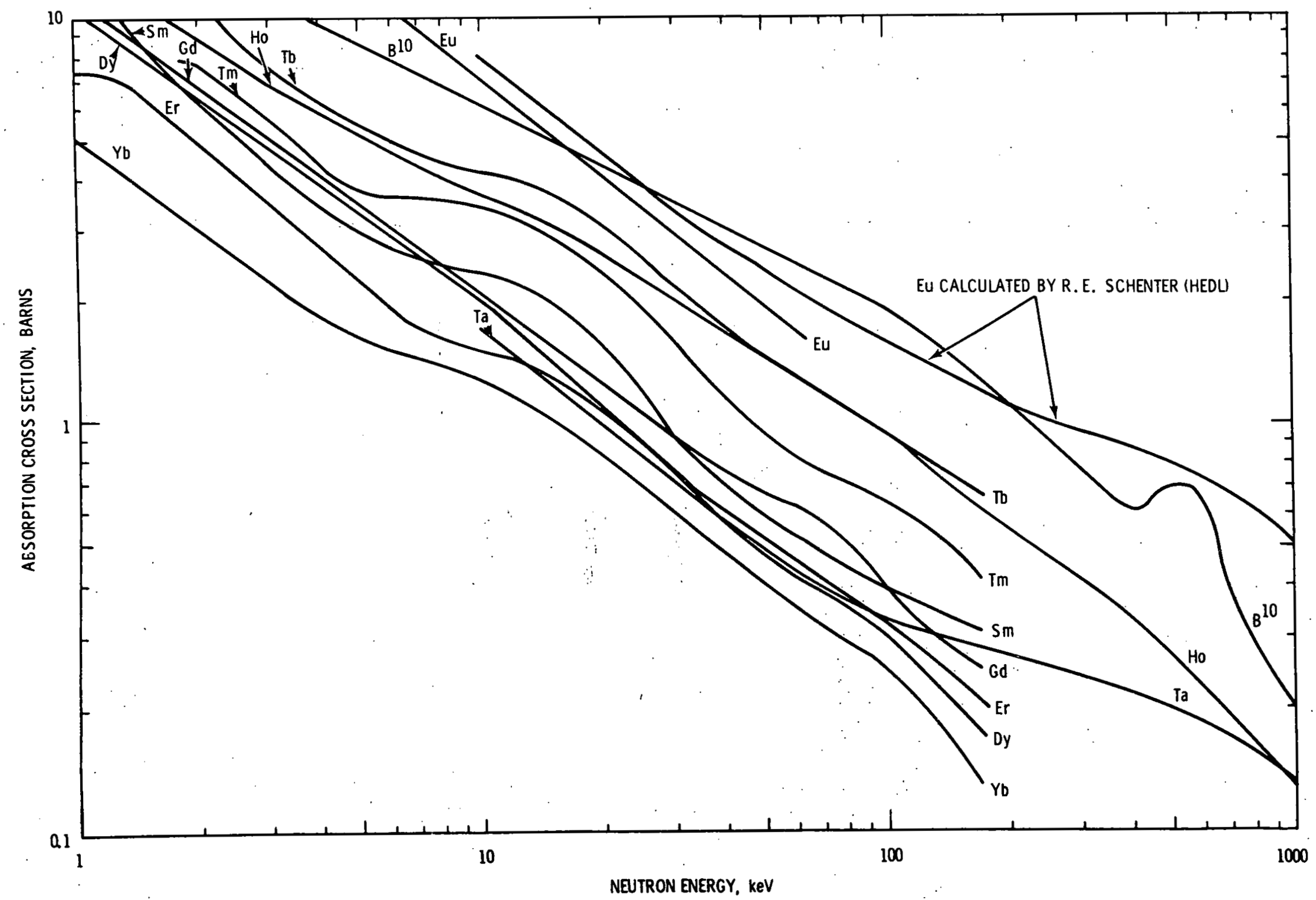

FIGURE 1. $n, \gamma$ cross sections for the natural isotopic abundance of several elements and the $n, \alpha$ cross section for $B^{10}$. 


\section{COSTS OF RARE EARTH OXIDES}

Eu is one of the rarest of the RE and is, therefore, rather expensive.Table I lists the relative abundance of RE in the mineral bastnasite, which is the principal source of RE, and i.t. also lists current prices of the 99.9\% pure oxides. These figures, as well as other information on availability, were obtained from Molybdenum Corporation of America (Molycorp) which is the leading producer of RE in the United States. Prices in Table I are based on quantities of a few pounds. In lots of 1000 pounds or greater, the price of $\mathrm{Eu}_{2} \mathrm{O}_{3}$ would be $\sim \$ 365$ per pound. Similar cost reductions would probably apply to large quantities of the other oxides as well.

It is necessary, at this point, to delve briefly into the complex cost structure of the RE. The cost of a given RE is controlled to a large extent by the volume of sales of the other RE with which it occurs. Light RE tend to occur in one type of mineral, bastnasite for example, while the heavy RE tend to occur in other types of minerals. (5) The cost of $\mathrm{Eu}_{2} \mathrm{O}_{3}$ has come down by a factor of three or more in the last few years because of its increased use by the television industry. Simultaneously, however, there has been a large increase in the use of other RE. If it were not for this latter fact, the cost of $\mathrm{Eu}_{2} \mathrm{O}_{3}$ would not have realized the cost reduction that it has. It is important to realize that this balance in sales is necessary to maintain the costs of all the elements at a reasonable level. If there were a large demand for one particular element that was out of balance with the remaining elements, its cost would probably increase again.

The current 1973 production rate of RE oxides by Molycorp is $\sim 20,000$ tons per year of which somewhat less than 10 tons per year is $\mathrm{Eu}_{2} \mathrm{O}_{3}$. The demand for $\mathrm{Eu}_{2} \mathrm{O}_{3}$ could perhaps double with little effect on its cost. In fact, it might make it slightly cheaper. An even greater demand for $\mathrm{Eu}_{2} \mathrm{O}_{3}$ however, would begin to raise its cost unless there was a simultaneous increase in demand for the other RE. 
Mixtures of RE oxides (referred to as concentrates) are substantially cheaper than the pure oxides and there seems to be no reason not to consider these for control materials. A Sm/Gd concentrate containing the oxides of these two elements in the approximate ratio of $7 / 3$ selis for $2 \$ 15$ per pound. Another concentrate with the approximate ratio $1 \mathrm{Eu} / 2$. Gd/5. Sm sells for $\sim \$ 40-\$ 50$ per pound. Eu concentrate containing $92 \% \mathrm{Eu}_{2} \mathrm{O} 3,3 \%$ each of $\mathrm{Sm}_{2} \mathrm{O}_{3}$. and $\mathrm{Gd}_{2} \mathrm{O}_{3}$ and the rest $Y$ and the heavy RE oxides sells for $\sim \$ 300$ per pound.

Based on the same type of cost comparison described in Section $A$, use of the Eu concentrate instead of pure $\mathrm{Eu}_{2} \mathrm{O}_{3}$ would result in a savings of $\sim \$ 170,000$ per $1000 \mathrm{MW}(\mathrm{e})$ LMFBR with probably not more than $5 \%$ reduction in worth. It is not possible to comment on the worths of the other two concentrates, but potential raw materials cost savings of several hundred thousand dollars per 1000 MW(e) LMFBR would seem to provide enough incentive to determine their reactivity worths via measurements and/or calculations.

\section{MATERIALS PROPERTY CONSIDERATIONS}

Two other areas, besides economics and physics, must be taken into account if $\mathrm{RE}$ oxides other than $\mathrm{Eu}_{2} \mathrm{O}_{3}$ are to be considered for control materials. These are materials properties and radiation effects. The RE sesquioxides have remarkably similar chemical and physical properties and presumably would behave similarly in a radiation environment. Mixtures of the sesquioxides in any proportion should also perform satisfactorily as control materials. However, there are some subtle differences that must be considered.

The density of the monoclinic form of the sesquioxides is $\sim 8 \%$ higher than the cubic form and it might, therefore, be the more desirable form for control materials because it would have a higher worth per unit volume. The cubic-monoclinic crystalline transformation temperature increases from $\sim 850^{\circ} \mathrm{C}$ for $\mathrm{Sm}_{2} \mathrm{O}_{3}$ to $22200^{\circ} \mathrm{C}$ for $\mathrm{Dy}_{2} \mathrm{O}_{3} .^{(6,7)}$ Although monoclinic is the higher-temperature form, it is stable at low temperatures once it is formed. Apparently, the transformation is reversible only in the presence of water 
as a catalyst. (6:) one might suspect, however, that radiation would provide the necessary energy to cause transformation back to the cubic form at the lower temperatures. By analogy with the actinide sesquioxides, however, the reverse may in fact be true. Self-radiation damage from the alphadecay of $\mathrm{Cm}^{244}$ has been shown $(7,8)$ to cause a transformation from the cubic to the hexagonal form of $\mathrm{Cm}_{2} \mathrm{O}_{3}$ at room temperature. The hexagonal structure is an even higher temperature form than the monoclinic. $(6,7)$ obviously this problem will have to be studied prior to use of any of the RE sesquioxides. as control materials. Some results should be available early in 1974 when HEDL discharges some $\mathrm{Eu}_{2} \mathrm{O}_{3}$ pellets from the EBR-II where they will have been irradiated for 2225 full power operating says. Four cubic and four monoclinic $\mathrm{Eu}_{2} \mathrm{O}_{3}$ pellets are being irradiated at $670^{\circ} \mathrm{C}$ and $715^{\circ} \mathrm{C}$, respectively.

The sesquioxides of $\mathrm{Nd}, \mathrm{Pm}$, and $\mathrm{Sm}$ become hydrated upon exposure to atmospheric moisture. (10) Apparently $\mathrm{Eu}_{2} \mathrm{O}_{3}$ does not form a hydrate even in direct contact with water ${ }^{(11)}$ and presumably the heavy RE oxides don't either. If control materials containing $\mathrm{Sm}_{2} \mathrm{O}_{3}$ were considered, this hydration would have to be prevented and the effect of possible hydration upon the cubic-monoclinic transformation would have to be investigated.

It is worth noting here that the fabrication of RE oxide pellets could probably take advantage of the technology which has been built up for the fabrication of oxide fuel pellets. As mentioned in Section $A$, the costs involved in sintering, for example, are substantially less than those of hot-pressing which is required for the fabrication of $\mathrm{B}_{4} \mathrm{C}$ pellets.

\section{CONCLUSIONS AND RECOMMENDATIONS}

From the standpoint of cost and availability, the RE oxide concentrates of $\mathrm{Sm} / \mathrm{Gd}, E u / \mathrm{Sm} / \mathrm{Gd}$, and $E u$ in descending order, appear to be the best alternatives to pure $\mathrm{Eu}_{2} \mathrm{O}_{3}$ as fast reactor control materials. although the oxides of Tb, Dy, and Ho may also have potential. Because the reactivity worths of these materials cannot be determined with available cross section information, no estimate of the relative economic merits of 
these materials can be made. However, because a 1000 MW(e) LMFBR would contain nearly one million dollars worth of pure $\mathrm{Eu}_{2} \mathrm{O}_{3}$ as control material, it appears that there may be potential for savings amounting to a few hundred thousand dollars per reactor.

Cross sections and reactivity worths can be calculated for RE for $\sim \$ 10,000$ per element. In view of the potential savings, the investment certainly looks worthwhile. It is, therefore, recommended that such reactivity worth calculations be initiated. $\mathrm{Sm}$ and Gd should receive the highest priority although it would probably also be worthwhile to calculate the worths of Tb, Dy, and Ho on a somewhat lower priority basis.

If the results of the worth calculations look favorable, a more detailed economic analysis, as well as studies of certain materials properties, should be performed. Materials properties that are of interest include the cubic-monoclinic transformation characteristics of RE oxide mixtures and an investigation to determine whether mixtures containing $\mathrm{Sm}_{2} \mathrm{O}_{3}$ tend to hydrate and, if so, whether this has any effect on the cubic-monoclinic transformations. Finally, one would need to study the compatibility of the RE oxides with the cladding and to investigate the effect of reactor irradiation on the phase transformation, thermal conductivity, and dimensional stability. 


\section{REFERENCES}

1. "1000 MWe LMFBR Follow-on Study, Tasks II and III," Westinghouse Conceptual Design Report, C. E. Shufelt (ed.), WARD-2000-97 (1969).

2. R. J. Tuttle and T. H. Springer, Nucl. Sci. Eng. 49 (1972).

3. M. D. Goldberg, et al., "Neutron Cross Sections," BNL-325, 2nd ed. Supplement No. 2, Vol. I (1964) and Vol. II (1966).

4. The Reactor and Safety Engineering Department of Westinghouse Hanford Company, Richland, Washington is currently calculating cross sections and reactivity worth of Eu in a typical LMFBR spectrum. R. E. Schenter of that Department has estimated that similar calculations could be made for other rare earth elements and that these calculations could be extended to include a typical GCFBR spectrum for $\backsim \$ 10,000$ per element.

5. E. V. Kleber and B. Love, "The Technology of Scandium, Yttrium, and the Rare Earth Metals, Pergamon Press, New York (1963).

6. H. R. Hoekstra, Inorg. Chem. 5,754 (1966).

7. T. D. Chikalla, C. E. McNeilly, J. L. Bates, and J. J. Rasmussen, "High Temperature Phase Transformation in Some Lanthanide and Actinide Oxides," Centre National de la Recherche Scientifique, Publication No. 205 (1973).

8. J. C. Wallmann, J. Inorg. Nucl. Chem. 26, 2053 (1964).

9. A. L. Pitner, Westinghouse Hanford Co., Richland, Washington, Private Communication.

10. H. T. Fullam and F. P. Roberts, "Reactions of the Sesquioxides of Pm, $\mathrm{Nd}$, and Sm with Water," BNWL-1421 (1970).

11. W. A. Ross, Westinghouse Hanford Co., Richland, Washington, Private Communication. 


\section{DISTRIBUTION}

\section{BATTELLE-NORTHWEST}

N. E. Carter

T. D. Chikalla

D. L. Condotta

J. W. Finnigan

W. J. Gray (10)

R. E. Heineman

B. R. Leonard

R. C. Liikalla

D. F. Newman
HEDL

J. A. Christensen

R. E. Dah1

P. L. Hofmann

R. E. Schenter 